\title{
Electrochemical Reduction of Carbon Dioxide Catalyzed by Cofacial Dinuclear Metalloporphyrin
}

\author{
Osamu ENOKI, Takane IMAOKA, and Kimihisa YAMAMOTO* \\ Department of Chemistry, Faculty of Science \& Technology, Keio University (Yokohama 223-8522, Japan)
}

Received October 11, 2002 ; Accepted December 25, 2002

\begin{abstract}
Electroreduction of carbon dioxide was homogeneously carried out using cofacial dinuclear metalloporphyrin CoTMPyP-MTPPS. The reduction was catalyzed by Co(l)TMPyP which generated at $-1.8 \mathrm{~V} \mathrm{vs.} \mathrm{Ag} / \mathrm{Ag}^{+}$. More excellent catalytic activity was observed in the presence of $\mathrm{H}_{2} \mathrm{O}$ in comparison with that for mononuclear one. The catalytic activity depended on the central metal of TPPS because they worked as an electron mediator.
\end{abstract}

Key Words : Cofacial Porphyrin, Electrochemical Reduction, Carbon Dioxide, Homogeneous Catalyst

\section{Introduction}

The reduction of carbon dioxide has interested many researchers because it simultaneously provides both an abundant carbon source and effective solution of global warming. Electrochemical methods are useful for this purpose, but carbon dioxide requires a very negative potential to be reduced due to its high overpotential, and the main products were two-electron reduction compounds, e.g., formic acid. ' To overcome these problems, various metal complexes were investigated as homo/heterogeneous catalysts. ${ }^{2}$ Here we use a cofacial dinuclear metalloporphyrin (Fig.1) as the catalyst, which are conveniently prepared and found that it is a very effective multi-electron transfer catalyst for the reduction of carbon dioxide, even though the mononuclear metalloporphyrin was extensively investigated as a catalyst for the reduction of carbon dioxide and its reduction mechanism is known. ${ }^{3}$

\section{1 Chemicals}

\section{Experimental}

The free base porphyrins were purchased from Tokyo Kasei Inc. and other chemicals were from Kantoh Chemical Company Inc. All materials were reagent grade and used as received. $(5,10,15,20$-Tetrakis ( $\mathrm{N}$-methyl-4pyridinio)porphyrinato)cobalt(II) (CoTMPyP) and (5,10, 15,20-tetrakis ( 4 -sulfonatophenyl) porphyrinato) cobaltate (II) (CoTPPS) were prepared as described before. ${ }^{4)}$

Other metalloporphyrins (MTPPS, $\mathrm{M}=$ metal) were synthesized in the similar method of CoTPPS. $\mathrm{H}_{2}$ TPPS $4 \mathrm{Na}$ and one equivalent metal(II) salt(chloride or acetate) were refluxed in polar solvent $\left(\mathrm{H}_{2} \mathrm{O}\right.$ or DMF) under a $\mathrm{N}_{2}$ atmosphere. The products were purified by chroma-

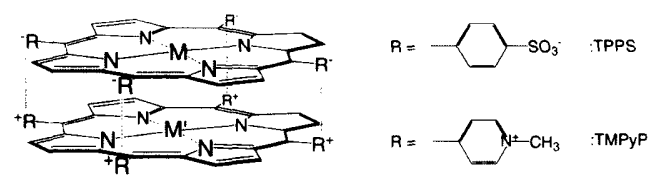

Fig. 1 Cofacial dinuclear metalloporphyrin. tography (Merck basic alumina/ $\mathrm{MeOH}-\mathrm{H}_{2} \mathrm{O}$ ) or reprecipitation after cation exchange(Amberlite GC 120, $\mathrm{Na}^{+}$ form). Every reaction and the fraction of chromatography was monitored by UV-vis spectra compared its maximum wavelength and absorption coefficient with the reference value. ${ }^{5}$ The products were obtained as M(III)TPPS $(\mathrm{OH})$ - $4 \mathrm{Na}$ form estimated from UV-vis data in the cases of $\mathrm{Cr}, \mathrm{Mn}$ and $\mathrm{Fe}$ porphyrin.

Cofacial dinuclear metalloporphyrins (CoTMPyPMTPPS) to measure their catalytic activities were prepared by mixing equal equivalent of each ionic porphyrin solution. The formation of dinuclear complex was identified by MALDI TOF-MS and Job's method based on UVvis spectra as described ${ }^{4)}$ and the dimerization equilibrium constants were estimated to be $c a .10^{6}\left(\mathrm{~mol} \mathrm{dm}^{-3}\right)^{-1}$ in DMSO.

\section{2 Spectroscopic measurements}

The UV-vis spectra were obtained using a Shimadzu UV-2400PC spectrometer with a quartz cell (optical path length: $1 \mathrm{~cm}$ ). MALDI TOF-MS were obtained on a Shimadzu/Krato KOMPACT MALDI mass spectrometer. Dithranol was used as a matrix.

\section{3 Electrochemical measurements}

The electrochemical analysis was performed using an electrochemical work station (BAS Co. Ltd., Model 660) under the following conditions.

Cyclic voltammetry was carried out in a conventional two-compartment cell. Solution for the measurement was prepared by dissolving a porphyrin complex and a tetraethylammonium perchlorate(TEAP) in pure DMSO or aqueous DMSO $\left(\mathrm{H}_{2} \mathrm{O}: \mathrm{DMSO}=1: 9(\mathrm{v} / \mathrm{v})\right)$ then bubbled by $\mathrm{Ar}$ or $\mathrm{CO}_{2}$ gas for $30 \mathrm{~min}$. The atmosphere was kept during the measurement to flow each gas. A $3 \mathrm{~mm}$ diameter glassy carbon disk electrode was used as the working electrode and polished with $0.05 \mathrm{~mm}$ alumina paste before the experiments. The auxiliary electrode was a coiled platinum wire separated from the working electrode by a fine-porosity frit. The reference electrode was $\mathrm{Ag} / \mathrm{Ag}^{+}$. The formal potential was normalized to the 
ferrocene-ferrocenium couple in acetonitrile.

Rotating disk voltammetry was carried out using the same instruments and conditions but a $6 \mathrm{~mm}$ diameter glassy carbon electrode was used as the working electrode. The disk rotation rate was $1000 \mathrm{rpm}$.

The reduction products were qualitatively detected by gas chromatography (Shimadzu GC-14 B) for carbon monoxide and hydrogen, and by colouriometric test for formaldehyde. ${ }^{6 \text { ? }}$

\section{Results and Discussion}

Cofacial dinuclear metalloporphyrins were synthesized from the anionic (tetra(4-sulfonatophenyl)porphyrin, TPPS) and the cationic (tetrakis(N-methylpyridil) porphyrin,TMPyP) porphyrin that had been previously metallated. ${ }^{4}$ Cyclic voltammograms(CV) of the dinuclear cobalt complex under Ar showed many reversible redox waves at -1.0 to $-1.5 \mathrm{~V}$ and at $-1.8 \mathrm{~V}$ vs. $\mathrm{Ag} / \mathrm{Ag}^{+}$(Fig. 2). This latter wave became irreversible and the reductive current was increased in a $\mathrm{CO}_{2}$ atmosphere, which indicates that the reduction of $\mathrm{CO}_{2}$ takes place. ${ }^{3)}$ This reductive current change was clearer with the addition of water to the solvent, because the reduction process needs a proton donor, ${ }^{7)}$ therefore water played the role as a proton source. Long time bulk electrolysis results in the formation of carbon monoxide, hydrogen, and formaldehyde as the reduction products.

To quantitatively compare the catalytic activity of the dinuclear complex with that of the mononuclear complex, rotating disk voltammetry(RDV) was measured for each porphyrin. In some cases, the voltammograms showed two steps of the limiting current. For example, the voltammogram of the mononuclear CoTMPyP solution obviously showed the first plateau current at $-2.0 \mathrm{~V}$. Then the current was increased again at $-2.1 \mathrm{~V}$ and showed the second limiting current at $-2.4 \mathrm{~V}$. The current increase at $-2.1 \mathrm{~V}$ was also observed for the blank solution, i.e. a solution containing only the supporting electrolyte, so that was originated from the heterogeneous direct reduction of carbon dioxide at the electrode surface.

The RDV results(Table 1) show that the limiting current of the dinuclear complex was about twice greater

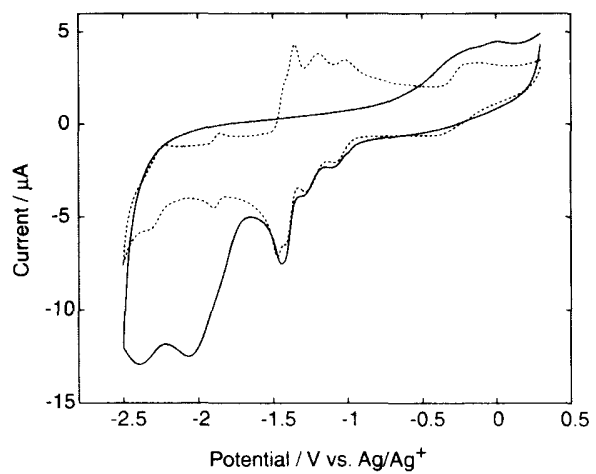

Fig. 2 Cyclic Voltammograms of $0.5 \mathrm{mM}$ CoTMPyPCoTPPS in DMSO-water(9:1) under Ar(dotted) and $\mathrm{CO}_{2}$ (bold). Supporting electrolyte; 0.2 M TEAP, Scan rate; 20 $\mathrm{mVs}^{-1}$. $\left(\mathrm{M}=\mathrm{mol} \mathrm{dm}^{-3}\right)$.
Table 1 The results of RDV; current $(\mu \mathrm{A})$ at $-2.0 \mathrm{~V}$ and $2.3 \mathrm{~V}$ vs. $\mathrm{Ag} / \mathrm{Ag}^{+}$for each porphyrin complex in aqueous or non-aqueous DMSO.

\begin{tabular}{ccccc}
\hline & \multicolumn{2}{c}{ Non aqueous } & \multicolumn{2}{c}{$10 \% \mathrm{H}_{2} \mathrm{O}$ Addition } \\
porphyrin & $-2.0 \mathrm{~V}$ & $-2.3 \mathrm{~V}$ & $-2.0 \mathrm{~V}$ & $-2.3 \mathrm{~V}$ \\
\hline Blank & 0.40 & 3.58 & 0.80 & 9.14 \\
CóTPPS & 0 & 4.95 & 1.08 & 19.6 \\
CoTMPyP & 2.09 & 4.77 & 17.3 & 34.6 \\
Co-Co & 2.65 & 9.54 & 22.3 & 67.8 \\
\hline
\end{tabular}

than the simple sum of the mononuclear one. Therefore, it is obvious that the catalytic activity for the reduction is enlarged by dinuclearization.

From the RDV results, CoTMPyP has catalytic activity but CoTPPS does not. The CV of each charged porphyrin measured in the same conditions showed three simple kinds of redox waves for CoTPPS at $0.3,-1.2$, and $-2.4 \mathrm{~V}$ vs. $\mathrm{Ag} / \mathrm{Ag}^{+}$which were attributed to $\mathrm{Co}(\mathrm{III} / \mathrm{II})$, $\mathrm{Co}(\mathrm{II} / \mathrm{I})$, and $\mathrm{Co}(\mathrm{I} / 0)$, respectively, ${ }^{8)}$ but the $\mathrm{Co}(\mathrm{III} / \mathrm{II})$ and $\mathrm{Co}(\mathrm{II} / \mathrm{I})$ waves did not change under $\mathrm{Ar}$ and $\mathrm{CO}_{2}$. Generally $\mathrm{CO}_{2}$ reduction is homogeneously catalyzed by $\mathrm{Co}(0)$ porphyrin, but in our case $\mathrm{Co}(0)$ was unable to generate at $-1.8 \mathrm{~V}$ vs. $\mathrm{Ag} / \mathrm{Ag}^{+}$, where the current increased. Taking into account the potential, Co(0)TPPS was not utilized in this catalysis. CoTMPyP had many redox waves at -1.0 to $-1.5 \mathrm{~V}$, which identified as the six-electron reduction of the methylpyridinium groups and the porphyrin ring of TMPyP, and at $-1.8 \mathrm{~V}$ vs. Ag $\mathrm{Ag}^{+}$. The redox properties of CoTMPyP have already been reported in detail ${ }^{9 /}$ and described that TMPyP maintains the $\mathrm{Co}$ (II) valance state at that potential. The redox wave at $-1.8 \mathrm{~V}$ vs. $\mathrm{Ag} / \mathrm{Ag}^{+}$was estimated to be due to the $\mathrm{Co}$ (II)/(I) couple. The catalytic active species is Co(I)TMPyP. CoTPPS acts as an electron mediator to CoTMPyP during the reduction. ${ }^{10)}$

The main catalytic center was CoTMPyP based on the mechanism suggesting that the catalyst maybe becomes more active allowing the use of other metal elements than cobalt. The catalyses of CoTMPyP-MTPPS were measured by $\mathrm{RDV}$, where $\mathrm{M}$ were various transition metals. The limiting current of the RDV revealed that the catalysis was facilitated when the central metal of the MTPPS was either cobalt or copper(Fig.3). However for the other metals, the catalysts were nearly equal or even

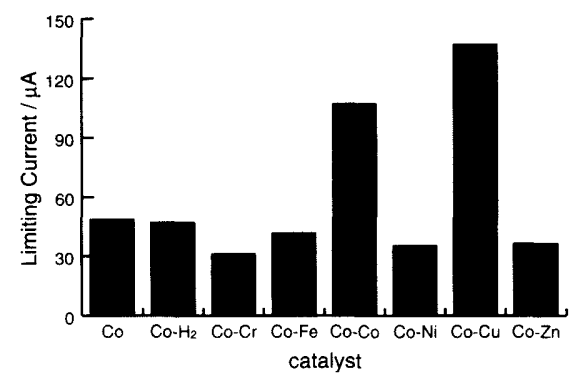

Fig. 3 The changes of maximum limiting currents of RDV; where CoTMPyP-MTPPS complex is abbreviated to Co-M ( $\mathrm{Co}-\mathrm{H}_{2}$ means CoTMPyP-H $\mathrm{H}_{2}$ TPPS) and "Co" means mononuclear CoTMPyP. 
less active by dinuclearization. This difference was due to the ability of the central metal to be an electron mediator. The redox potentials of the catalyst and the electron mediator were so close that multi-electron transfer readily occurred.

\section{Conclusion}

Cofacial dinuclear metalloporphyrins were synthesized and their catalytic activity for the reduction of carbon dioxide was electrochemically demonstrated. Co(I)TMPyP possesses an excellent catalytic activity, which was emphasized by the dinuclearization with CoTPPS or CuTPPS which acts as an electron mediator.

\section{Ackowledgement}

This work was partially supported by a Grant-in-Aid for Scientific Research (Nos. 13022263, 13555261) and the $21^{\text {ST }}$ COE Program(Keio-LCC) from the Ministry of Education, Science, Culture and Sports, and a Grant-in-Aid for Evaluative Technology (12407) from the Science and Technology Agency, and Kanagawa Academy Science and Technology Research Grant(Project No. 23).

\section{References}

1) C. Amatore and J. -M. Savéant, J. Am. Chem. Soc., 103, 5021 (1981).

2) J. P. Collin and J. P. Sauvage, Coord. Chem. Rev., 93, 248, (1989); J. Costamagna, G. Ferraudi, J. Canales, and J. Vargas, Coord. Chem. Rev., 148, 221 (1996).

3) I. Bhugun, D. Lexa, and J.-M. Savéant, J. Am. Chem. Soc., 118, 1769, (1996); According to this reference, the reduction product $(\mathrm{CO})$ was adsorbed on the electrode surface so the $\mathrm{CV}$ showed an irregular curve.

4) K. Yamamoto, S. Nakazawa, A. Matsufuji, and T. Taguchi, J. Chem. Soc., Dalton Trans., 251 (2001).

5) P. Hambright, The porphyrin handbook (Eds. K. M. Kadish, K. M. Smith, and R. Guilard), Vol.3, Academic Press, San Diego, CA, Chap.18 (2000).

6) R. H. Still, K. Willson, and B. W. J. Lynch, Analyst, 93, 805 (1968).

7) I. Bhugun, D. Lexa, and J.-M. Savéant, J. Phys. Chem., 100, 19981 (1996).

8) D. Behar, T. Dhanasekaran, P. Neta, C. M. Hosten, D. Ejeh, P. Hambright, and E. Fujita, J. Phys. Chem. A, 102, 2870 (1998).

9) C. Araullo-McAdams and K. M. Kadish, Inorg. Chem ., 29, 2749 (1990).

10) T. Imaoka and K. Yamamoto, Phys. Chem. Chem. Phys., 3, 4462 (2001). 